\title{
Shear bond strength of partial coverage restorations to dentin
}

\author{
Juan-Luis Román-Rodríguez ${ }^{1}$, Rubén Agustín-Panadero ${ }^{1}$, Jorge Alonso-Pérez-Barquero ${ }^{2}$, Antonio Fons-Font ${ }^{3}$, \\ María-Fernanda Solá-Ruíz ${ }^{1,4}$
}

\author{
${ }^{1}$ Associate Lecturer. Department of Dental medicine, Prosthodontic and Occlusion Teaching Unit, University of Valencia, Univer- \\ sity of Valencia General Studies (UVGS), Spain \\ ${ }^{2}$ Lecturer in Prosthodontics. Prosthodontic and Occlusion Teaching Unit, UVGS, Spain \\ ${ }^{3}$ Assistant Lecturer. Department of Dental medicine, Prosthodontic and Occlusion Teaching Unit, UVGS, Spain \\ ${ }^{4}$ Senior Lecturer. Department of Dental medicine, Prosthodontic and Occlusion Teaching Unit, UVGS, Spain
}

\author{
Correspondence: \\ Unidad de Prostodoncia y Oclusión \\ Departamento de Estomatologia \\ Edificio Clínica Odontológica \\ C/ Gascó Oliag, 1 \\ 46010 - Universitat de València, Spain \\ juanluis.romanrodriguez@gmail.com
}

Received: $24 / 03 / 2015$

Accepted: 16/04/2015

Román-Rodríguez JL, Agustín-Panadero R , Alonso-Pérez-Barquero J, Fons-Font A, Solá-Ruíz MF. Shear bond strength of partial coverage restorations to dentin. J Clin Exp Dent. 2015;7(3):e396-9. http://www.medicinaoral.com/odo/volumenes/v7i3/jcedv7i3p396.pdf

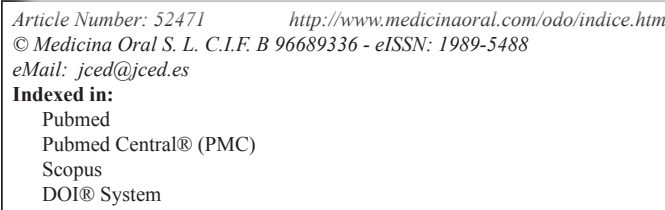

\begin{abstract}
Background: When partial coverage restorations (veneers, inlays, onlays...) must be cemented to dentin, bond strength may not reach the same predictable values as to enamel. The purpose of this study was: 1 . To compare, with a shear bond test, the bond strength to dentin of a total-etch and a self-etching bonding agent. 2. To determine whether creating microretention improves the bond strength to dentin.

Materials and methods: Two bonding agents were assayed, Optibond FL $₫($ Kerr), two-bottle adhesive requiring acid etching, and Clearfil SE Bond ${ }^{\circledR}$ (Kuraray), two-bottle self-etching adhesive. The vestibular, lingual, distal and mesial surfaces of ten molars $(n=10)$ were ground to remove all enamel and 40 ceramic samples were cemented with Variolink II ${ }^{\circledR}$ (Ivoclar Vivadent). Half the molar surfaces were treated to create round microretention (pits) to determine whether these could influence bond strength to dentin. The 40 molar surfaces were divided into four groups $(\mathrm{n}=10)$ : Optibond FL (O); Clearfil SE (C); Optibond FL + microretention (OM); Clearfil SE + micro retention (CM). A shear bond test was performed and the bond failures provoked examined under an optical microscope.

Results: $\mathrm{O}=35.27 \pm 8.02 \mathrm{MPa} ; \mathrm{C}=36.23 \pm 11.23 \mathrm{MPa} ; \mathrm{OM}=28.61 \pm 6.27 \mathrm{MPa} ; \mathrm{CM}=27.01 \pm 7.57 \mathrm{MPa}$. No statistically significant differences were found between the adhesives. Optibond FL showed less statistical dispersion than Clearfil SE. The presence of microretentions reduced bond strength values regardless of the adhesive used.

Conclusions: 1. Clearfil SE self-etching adhesive and Optibond FL acid-etch showed adequate bond strengths and can be recommended for bonding ceramic restorations to dentin. 2 . The creation of round microretention pits compromises these adhesives' bond strength to dentin.
\end{abstract}

Key words: Adhesion to dentin, bonding agent, Optibond FL, Clearfil SE, microretention, shear bond test.

\section{Introduction}

The mechanisms of bonding to enamel have been well known for some 50 years, and provide stable and predictable unions. On the contrary, bonding to dentin remains a topic for research that aims to achieve outcomes comparable to enamel $(1,2)$.

Current dental practice is based on minimally invasive treatments often involving bonding procedures. Partial 
coverage restorations (veneers, inlays, onlays, overlays...) are retained by adhesion, and bond strength must be optimized and debonding avoided $(3,4)$. Partial restorations in the anterior sector (veneers, laminates), being a more conservative treatment than full coverage restorations, are usually bonded to enamel as the main substrate. But in the posterior sector there are certain situations whereby teeth requiring inlays, onlays or overlays may have greater areas of exposed dentin than of enamel. The same can occur in the anterior sector when the teeth have suffered vestibularization or giroversion and so need greater reduction.

Generally, bonding systems for enamel based on treatment with orthophosphoric acid, a primer, and a bonding agent, or total-etch (for example Optibond FL ${ }^{\circledR}$ [Kerr, Scafaty, Italy]) are the most recommendable because of the high bond strength they achieve (2,5-7). But when the main substrate is dentin, developmental research into bond systems has pointed to self-etching adhesives as the better option.

Given the evidence that bonding onto dentin produces less strength, the use of microretentions created when the teeth are prepared could be a method for improving the adhesion of partial coverage restorations by increasing the bond surface area and through the retentive capacity of the microretentions themselves.

-Objectives

1. To compare, by means of a shear bond test, the bond to dentin of a total-etch adhesive system and a self-etching system.

2. To determine whether the creation of microretentions improves bonding to dentin.

\section{Material and Methods}

Forty ceramic samples were fabricated $(3 \times 3 \mathrm{~mm} 2)$ (IPS e.max Press ${ }^{\circledR}$ [Ivoclar Vivadent, Schaan, Liechtenstein]) by pressure injection.

The vestibular, lingual, distal, and mesial surfaces of ten molars $(\mathrm{n}=10)$ were ground down with a diamond cutting disc to eliminate all enamel (Fig. 1). For half of the surfaces $(n=20)$, round microretentions were created (pits) in the middle of the prepared surfaces with a round diamond bur (Komet巴 S6801 014) (Fig. 2).

Two bonding agents were selected, Optibond FL $₫$, two-bottle, total-etch adhesive, which has been shown to produce a reliable bond to enamel7,8, and Clearfil SE Bond $\AA$ (Kuraray, Tokyo, Japan), a two-bottle, selfetching adhesive that has shown good bond strength values to dentin (7-9) (Table 1).

Four groups of ten samples $(n=10)$ were created: Optibond FL (O); Clearfil SE (C); Optibond FL + microretentions (OM); and Clearfil SE + microretentions (CM). All the ceramic samples were cemented with Variolink II ${ }^{\circledR}$ (Ivoclar Vivadent) resin cement with catalyst. Each molar had been prepared with four ground surfaces,

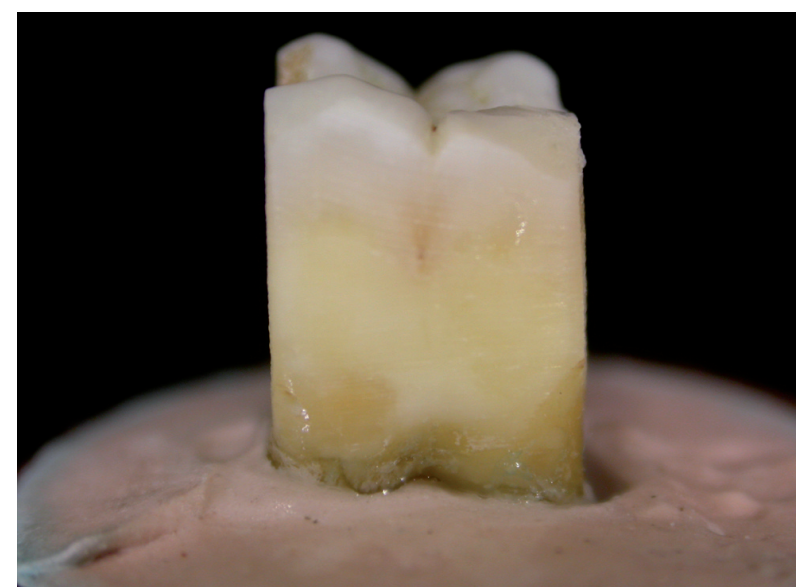

Fig. 1. Ground dentin surface.

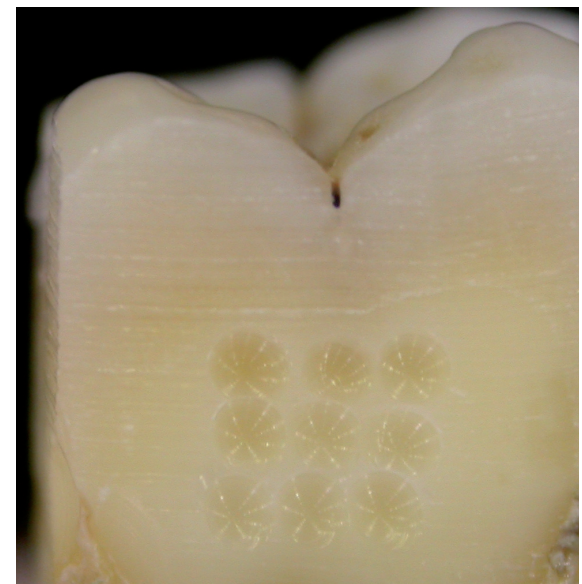

Fig. 2. Nine pits made in the surface to be bonded $\left(3 \times 3 \mathrm{~mm}^{2}\right)$.

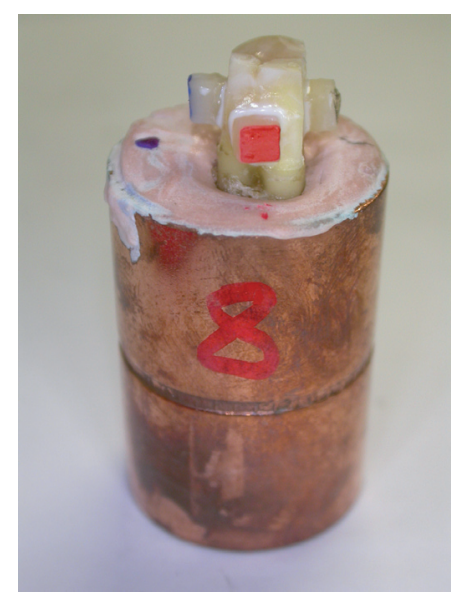

Fig. 3. Sample molar with four ceramic blocks cemented on four sides. 
Table 1. Treatment of ceramic and methods of application of each bonding agent.

\begin{tabular}{|c|c|c|}
\hline CERAMIC IPS e.max Press & ADHESIVE Optibond FL & ADHESIVE Clearfil SE \\
\hline $\begin{array}{l}\text { 1. Etching with } 4.9 \% \text { hydrofluoric acid for } 20 \\
\text { seconds. Rinse and dry. }\end{array}$ & $\begin{array}{l}\text { 1. Etching with } 37 \% \text { orthophosphoric acid, rinse for } \\
15 \text { seconds, dry for } 3 \text { seconds. }\end{array}$ & $\begin{array}{l}\text { 1. Apply primer for } 30 \text { seconds, gently } \\
\text { air-dry. }\end{array}$ \\
\hline $\begin{array}{l}\text { 2. Etching with } 37 \% \text { orthophosphoric acid for one } \\
\text { minute, rinse, and dry. }\end{array}$ & $\begin{array}{l}\text { 2. Apply primer for } 15 \text { seconds, air-dry for } 5 \\
\text { seconds }\end{array}$ & 2. Apply bonding agent, gently air-dry. \\
\hline $\begin{array}{l}\text { 3. Wash in distilled water in ultrasonic tank for } 5 \\
\text { minutes, and then dry. }\end{array}$ & $\begin{array}{l}\text { 3. Apply bonding agent for } 15 \text { seconds, air-dry for } \\
3 \text { seconds }\end{array}$ & 3. Photopolymerize for 10 seconds. \\
\hline 4. Silane application for 1 minute, and air-dry. & 4. Photopolymerize for 20 seconds. & \\
\hline 5. Adhesive application without polymerization. & & \\
\hline
\end{tabular}

and a sample from each group was cemented to each of the four sides (Fig. 3). The 10 molars were stored in a convection oven (J.P Selecta Digiheat 52L, Barcelona, Spain) for 24 hours with a humid atmosphere at $37^{\circ}$. Lastly, a shear bond test was performed with a universal test machine (Shimadzu model AG-x plus ${ }^{\circledR}$, Shimadzu corporation, Kyoto, Japan) with a cross-head speed of $0.5 \mathrm{~mm} / \mathrm{min}$. and cell charge of $1000 \mathrm{~N}$ (Fig. 4).

-Statistical analysis

Descriptive data of shear bond strength were calculated (mean, standard deviation, range, and median) for each group. Inferential analysis consisted of estimating a Brunner-Langer non-parametric model for correlated data. An ANOVA-type model was used to evaluate the main effects and interactions. The significance level was set at $5 \%(\alpha=0.05)$.

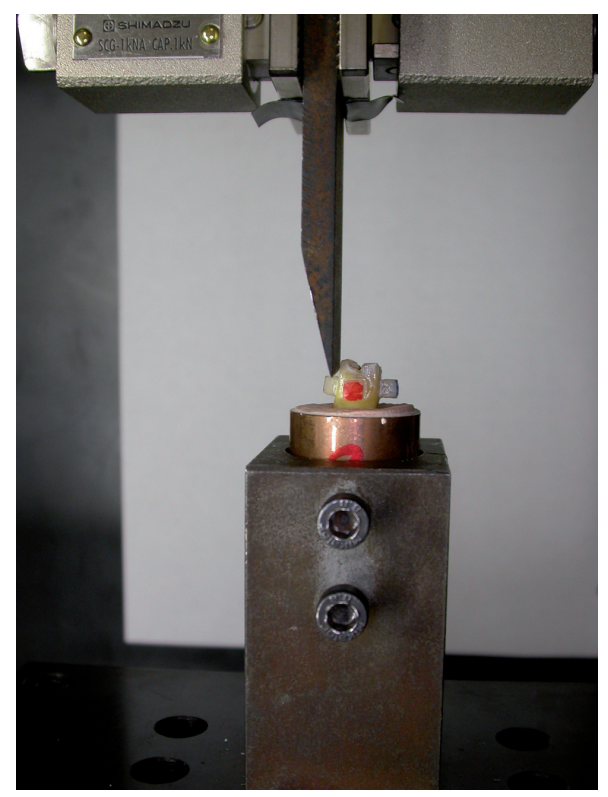

Fig. 4. Shear bond test.

\section{Results}

Bond strength values were similar for the two bonding agents without statistically significant differences. Optibond FL showed less statistical dispersion than Clearfil $\mathrm{SE}$. The creation of microretention pits in the dentin surfaces reduced bond strength values regardless of which bonding agent was used (Tables 2, 3, Fig. 5).

\section{Discussion}

Generally a microtensile bond strength test is preferable to a shear bond test in bond strength studies $(10,11)$, but in the case of the present study, microtensile testing was not a viable option due to the application of microretention pits. The microtensile test method involves making cuts of very small dimensions, so that some test cuts might have coincided with a retention pit, others a section of a pit, and others would cut across an area between pits, so that the total sample would not be homogenous or representative.

The results obtained by the two bonding agents did not show statistically significant differences, although there was slightly less statistical dispersion with Optibond FL, which suggests that it offers a more predictable and homogenous performance.

Improved retention and bond strength produced by creating slots, pits, or other similar retention shapes has been investigated in a number of studies that have observed improvements of $31-81 \%(12,13)$. However, the increase in surface area and the retention capacity of the pits used in the present study did not improve bond strength at all - in fact bond strength was reduced. Two possible mechanisms might explain this reduction in bond strength. The first is the formation of pores mainly inside the pits but after examination under the optical microscope, this hypothesis was discounted. The second cause lies in the shear forces, which were very similar, and has to do with the thickness of the adhesive as the volume of adhesive penetrating into the pits could undergo fracture at lower forces and so cause the overall reduction in bond strength observed. 
Table 2. Bond strength values by group.

\begin{tabular}{|c|c|c|c|c|c|c|}
\hline & $\mathbf{N}$ & Mean & $\begin{array}{c}\text { Standard } \\
\text { deviation }\end{array}$ & Minimum & Maximum & Median \\
\hline Clearfil & 10 & 36.23 & 11.26 & 17.65 & 53.31 & 36.56 \\
\hline Clearfil + Pits & 10 & 27.01 & 7.57 & 14.50 & 38.70 & 26.88 \\
\hline Optibond & 10 & 35.27 & 8.02 & 21.74 & 50.47 & 34.27 \\
\hline Optibond + Pits & 10 & 28.61 & 6.27 & 21.84 & 40.51 & 27.56 \\
\hline
\end{tabular}

Table 3. Results of ANOVA type test (ATT) for Brunner-Langer model.

\begin{tabular}{|l|c|}
\hline & $\boldsymbol{P}$-value (ANOVA type test) \\
\hline BOND AGENT & 0.853 \\
\hline PITS & $<0.001$ \\
\hline BOND AGENT + PITS & 0.685 \\
\hline
\end{tabular}

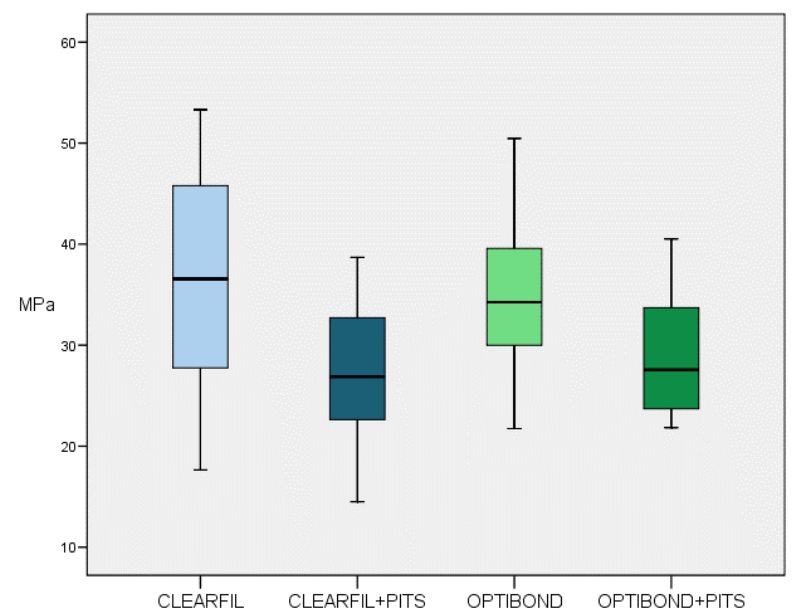

Fig. 5. Box-plot of value distribution of bond strength (MPa) by group.

The bond strength values obtained coincide with those published in the literature $(7,8,14)$. Although the work investigated two bonding systems whose bonding mechanisms are different, both were found to be equally valid as bonding agents for cases in which the main substrate is dentin (endodontically treated teeth, vestibularized teeth, cases of acute giroversion...).

-Clinical relevance

The data obtained show that the self-etching bonding agent Clearfil SE and the acid total etch bonding agent Optibond FL produce adequate bond strength values to dentin and can be recommended for cementing ceramic restorations that need bonding to this substrate. However, the creation of microretentions in the form of round pits is not recommendable as this technique was seen to reduce the bond strength of these agents to dentin.

\section{References}

1. Perdigao J, Reis A, Loguercio AD. Dentin adhesion and MMPs: A comprehensive review. J Esthet Rest Dent. 2013;25:219-41.

2. Poitevin A, De Munck J, Van Ende A, Suyama Y, Mine A, Peumans M, Van Meerbeek B. Bonding effectiveness of self-adhesive composites to dentin and enamel. Dent Mat. 2013;29:221-30.

3. Magne P. Immediate dentin sealing: a fundamental procedure for indirect bonded restorations. J Esthet Restor Dent. 2005;17:144-54.

4. Granell Ruíz M, Agustín Panadero R, Fons Font A, Román Rodríguez JL, Solá Ruíz MF. Influence of bruxism on survival of porcelain laminate veneers. Med Oral Patol Oral Cir Bucal. 2014;19:e426-32.

5. Flury S, Peutzfeldt A, Lussi A. Influence of increment thickness on microhardness and dentin bond strength of bulk fill resin composites. Dent Mat. 2014;30:1104-112.

6. Peumans M, De Munck J, Van Landuyt KL. A 13-year clinical evaluation of two three-step etch-and-rinse adhesives in non-carious Class-V lesions. Clin Oral Investig. 2012;16:129-37.

7. Walter R, Swift EJ Jr, Boushell LW, Braswell K. Enamel and dentin bond strengths of a new self-etch adhesive system. J Esthet Restor Dent. 2011;23:390-6.

8. Mortazavi V, Samimi P, Rafizadeh M, Kazemi S. A randomized clinical trial evaluating the success rate of ethanol wet bonding technique and two adhesives. Dent Res J (Isfahan). 2012;9:588-94.

9. Peumans M, De Munck J, Van Landuyt KL. Eight-year clinical evaluation of a two-step self-etch adhesive with and without selective enamel etching. Dent Mater. 2010;26:1176-84.

10. Amaral R, Özcan M, Bottino MA, Valandro LF. Microtensile bond strength of a resin cement to glass infiltrated zirconia-reinforced ceramic: the effect of surface conditioning. Dent Mater. 2006;22:283-90. 11. Della Bona A, Anusavice KJ, Shen C. Microtensile strenght of composite bonded to hot press ceramics. J Adhes Dent. 2000;2:30513.

12. Burgess JO, McCartney JG. Anterior retainer design for resin-bonded acid-etched fixed partial dentures. J Prosthet Dent. 1989;61:43336.

13. Saad AA, Claffey N, Byrne D, Hussey D. Effects of groove placement on retention /resistance of maxillary anterior resin-bonded retainers. J Prosthet Dent. 1995;74:133-9.

14. Dündar M, Özcan M, GöKÇe B, Cömlekoglu E, Leite F, Valandro LF. Comparison of two bond strengtht testing methodologies for bilayered all-ceramics. Dental Materials. 2007;23:630-6. 